\title{
"Everything about him was just perfect. And I fell in love instantly": \\ Life and Love in Welcome to Night Vale
}

\author{
Dawn Stobbart
}

In December 2016, Welcome to Night Vale celebrated its $100^{\text {th }}$ installment with an episode entitled "Toast". Featuring all of the voices that have appeared in Night Vale since its inception in June 2012, "Toast" is a celebration of the show and of the relationship between radio host Cecil Palmer and scientist Carlos as they get married. Welcome to Night Vale, as the chapters in this volume will attest, allows listeners to follow the (rather strange, surreal, and sometimes pedestrian) experiences of a community living in "a small desert town somewhere in the Southwestern United States." Night Vale is described as "the most scientifically interesting community in the US" (Fink and Cranor, Mostly Void 5), and the podcast routinely shows this to be true; delivered in twice monthly installments, the podcast is framed through the voice of Night Vale public radio host Cecil Palmer, as he conveys local news and happenings to the community, making them seem normal, and even mundane.

Whilst Night Vale is a place where strange events are commonplace and conspiracy theories are an accepted reality, it is also a place where "people" are accepted for who they are, whether that is a sentient patch of haze named Deb, or a glowing Cloud that is the head of the PTA. This acceptance is shown during the pilot episode, when Cecil describes the first time he sees Carlos, saying "he grinned and everything about him was perfect, and I fell in love instantly" (Fink and Cranor, Mostly Void 5). Cecil is from the outset established as a gay character; however, this is not the defining characteristic of Cecil, an unusual (but not unknown) stance in most media: Frederik Dhaenens cites several changes that have taken place in television production in his analysis of the television show Glee for example 
(Dhaenens). But, as Cecil Baldwin, the voice of Cecil Palmer, says in an interview, this is not usual as

\author{
Mainstream media has a tendency to let "gay" or "lesbian" or "transgender" \\ be that defining characteristic of characters without showing audiences the \\ person beyond that. We're more interested in showing our characters as \\ whole people, especially those in a long-term relationship with its rewards \\ and flaws and every silly, boring thing that makes love so beautiful. (Butcher)
}

In this chapter, I focus on how Welcome to Night Vale presents a community that accepts the diversity in its inhabitants, but also consider how it endorses attitudes of acceptance and understanding through the actions of the inhabitants themselves, particularly radio host Cecil, and how they treat each other. To do this, I will primarily use the podcast episodes, with reference to the 2015 novel, Welcome to Night Vale (Fink and Cranor, Night Vale), to consider the representations of gender, sexuality, and disability as they appear in the fictional community, creating an inclusive place where people can live and love in any way they choose.

In the introduction to the second volume of Welcome to Night Vale transcripts, The Great Glowing Coils of the Universe (Fink and Cranor, Coils), Cranor explains some of the reasons that he thinks Welcome to Night Vale has become such a success. These reasons include the release of episode 27: "First Date" (Fink and Cranor, Coils, 11-21). Regular listeners of the podcast had been privy to Cecil's feelings towards Carlos the Scientist since the first episode "Pilot" (Fink and Cranor, Mostly Void, 1-9), where, as cited above, Cecil relates his feelings towards the scientist that arrives in Night Vale, but these feelings do not appear to be reciprocated until the end of episode 25: "One Year Later" (Fink and Cranor, 
Mostly Void, 246-255). It was at about this point in the podcast that listening figures rose exponentially. The first year saw Welcome to Night Vale being downloaded approximately 150,000 times over 25 episodes; in the thirteenth month ( 2 episodes) — which includes "First Date"- this number grew to 2.5 million. (Fink and Cranor, Coils, xiv) It is in this episode that listeners become privy to "the culmination of the relationship between host Cecil Palmer and Carlos the scientist" (Fink and Cranor, Coils, xv), and which deviated from the norm in mainstream fiction. The key difference between this same-sex relationship and others in popular fiction, according to Cranor, is that in most of mainstream media, viewers, readers, and listeners engage with a "teased-out, will-they-won't-they, same-sex relationship," where "couples are drawn close but never allowed to get together as a loving couple" (Fink and Cranor, Coils, xvi). Welcome to Night Vale instead challenges heteronormative behavior by presenting "a couple that falls in love without getting hung up on outdated hetero-assumptive conditions" (Fink and Cranor, Coils, xvi) —assumptions that include the understanding that "if you are born with male genitalia ... you will behave in masculine ways, desire women ... have sex in what are thought to be normally active and insertive ways and within officially sanctioned contexts". (Warner, 37) It is interesting to note that not one character, in more than four years, has mentioned Cecil and Carlos being part of a same-sex relationship, even though Cecil openly discusses his relationship in most of the podcast episodes, supporting the concept of an open and accepting community.

Media that caters to the gay community sees the podcast as being actively supportive of diversity in all forms; an interview in The Advocate, an American LGTB interest magazine, reports that "Welcome to Night Vale has created a home for listeners of all different identities, ethnicities, and orientations," with "the relationship between Cecil ... and Carlos" (Wu) taking the center stage of the podcast. The article notes that while audiences "have made a big deal over each romantic gesture, the citizens of Night Vale ... couldn't care less that their 
community radio host is in a gay relationship." Dylan Moran, who provides the voice of Carlos concurs, remarking in the same interview that "Carlos and Cecil's relationship is the least weird thing about Night Vale" (Wu) and with the presence of five-headed dragons, secret police, and a faceless old woman who lives in your home, this statement is, without a doubt, true. The normativity of their relationship is highlighted throughout the podcast; the bond between the two characters is realistic in its depictions of their interactions with —and about - each other and they deal with the same issues present in any relationship, such as "negotiating schedules and habits that just sort of irk you about your partner" (Adri). Showing the relationship as being just like any other allows listeners (some of whom may be struggling to understand their own sexuality) to engage with same-sex relationships in a healthy way, and furthermore allows listeners who (may) have only been exposed to negative depictions of same-sex relationships to view them as normal — with the same challenges and highlights as any other. This is important; young people especially "are faced with a continual barrage of prejudicial ideology they hear too often" (Goldman 34), and are expected to "assume positions that are centered around the nuclear family and which are gendered, sexualized, and fixed in time and space" (Dhaenens 306). Welcome to Night Vale offers an alternative viewpoint, one that espouses openness and equality for all people, without the heteronormative agenda of 'reproduction, marriage, and longevity."(Dhaenens 306)

In episode 79: "Lost in the Mail" (Vee), Basimah Bishara shares her memories of her father, who left to fight in a space war, and is able to send home one letter per year. Most of the letters are, she says, "lists of ways I need to live my life" including the need to wear her hijab (which she does for mosque, but not often at school) and "not to kiss a boy until I was 16" (Vee), to which she interjects "well, I guess good news for him there," as she has "a girlfriend not a boyfriend.” As with Cecil and Carlos, Basimah does not need to state explicitly that she is gay, just as she doesn't explicitly state that she is Muslim; both of these 
things are just part of her life, aspects of her personality that are just that—aspects. Just asor even more - important than her sexuality and ethnicity is the fact that her father is away at war and as such is missing most of her childhood, not knowing for example, that she spent most of her fourteenth year recovering from a car accident. Once again, the podcast iterates that the sexuality of a character is merely part of their make-up, and that there are other defining things that construct a person.

When Night Vale first introduced Carlos the scientist as a speaking character, he was voiced by series writer Jeffrey Cranor (a straight white actor). However, in the first live performance of the podcast, Condos (Fink and Cranor, Mostly Void, 258-278), a new actor was introduced to play the role, one more in keeping with the characters ethnic and sexual identity. Although the narrative is delivered predominantly from the perspective of Cecil, the lives shows, and the large online fandom of Night Vale that had come into being by this time, led Cranor to reconsider his involvement as Carlos. In the introduction to episode 16: The Phone Call (Fink and Cranor, Mostly Void, 140-149) Cranor explains why he made the change: "Not casting white people in roles for people of color is the correct thing to do. It's not a noble or laudable thing to do. It is what you are supposed to do, so we corrected this, by casting a person of color in the role" (Fink and Cranor, Mostly Void, 140-41). Recent years have seen a controversy surrounding "racebent" or "whitewashed" casting, in which a white actor is cast in the role of a previously non-white character. Examples of this include the actress Scarlet Johansson playing the Japanese character The Major, Motoko Kusanagi, in The Ghost in the Shell (Sanders), adapted from the Anime series of the same name, or Benedict Cumberbatch playing the role of Asian character Khan Noonien Singh in Star Trek 2: Into Darkness (Abrams), and even straight actor Eddie Redmayne in the role of trans character Einar Wegener in The Danish Girl (Hooper). In choosing actors that resemble the characters they are playing, Fink and Cranor acknowledge the inherent discrimination in 
foregrounding white, heterosexual actors, when there are actors who are better suited to the roles, such as Dylan Marron who is a gay person of color-perfectly suited to play the role of Carlos, also a person of color who identifies as gay. As with sexuality, Welcome to Night Vale challenges behavior that discriminates against minorities, using actors that reflect the ethnicity of the character they are playing.

As shown earlier, many of the central aspects of Welcome to Night Vale were introduced in the first episode. As well as introducing the main characters of the podcast and an openly gay character in the main role, "Pilot" also establishes Night Vale as a place that is open to the presence of characters that might be described in popular fiction as "other"those who "are everything that lies outside" (Moosavinia, Lorestan and Ahmad 105) of the (hetero) normative self. There are hooded figures that the listener is asked not to approach or look at; there are angels living "out near the car lot" (Fink and Cranor, Mostly Void, 3) with Old Woman Josie (although the Night Vale City Council are quick to remind listeners that angels do not exist), and there is a faceless old woman who lives in your home-all of whom are accepted as Night Vale residents. This openness does not come at the cost of accepting of negative behaviors, however. Night Vale will not accept racism, for example, as can be seen through the presence of The Indian Tracker. This character is described as being of "maybe Slavic origin, yet [he] wears an Indian headdress out of some racist cartoon" (Fink and Cranor, Mostly Void, 6). His actions and beliefs are quickly shown to be intolerable when Cecil reports that, "it's really hard to take him seriously in that headdress" (Fink and Cranor, Mostly Void, 7). The racist overtones of the character (referred to after the pilot episode as the Apache Tracker) continue throughout the first year of the podcast, as does the refutation of the characters actions. In episode 7: "History Week" (Fink and Cranor, Mostly Void, 56-64), Cecil remarks that "I think I speak for everyone in the community when I say good riddance to that local embarrassment. He made the whole town look ignorant and racist" (Fink and 
Cranor, Mostly Void, 59) for example. Even when he is transformed into a Native America (who speaks Russian), he is still considered an "asshole"-just because he now wears the correct skin, his past indiscretions do not pardon him, and he is rightly treated as an outcast for his racism. In his final appearance, episode 25: "One Year Later" (Fink and Cranor, Mostly Void, 246-55), he is considered to be a "real racist jerk and no one likes him. ...He is the same embarrassment to our town he always was" (Fink and Cranor, Mostly Void, 249).

However, even he is redeemed. When Carlos is wounded by tiny people who live in a city under the bowling alley, it is the Apache tracker that rushes to save him, being mortally wounded in the process. After his death, Cecil comments, "How could I have been so wrong about this man? An embarrassment to our town? Maybe. A real jerk? Yes. But he was also a man with Night Vale's best interests at heart...And he, at the cost of his own life, saved Carlos...Tell me nothing else, and I will still tell you: Here is a good man" (Fink and Cranor, Mostly Void, 253-54). His sacrifice is rewarded with the erection of a monument, but this is tempered by it being "buried somewhere in the desert where no one will find it, because he was also a racist embarrassment and we don't want our town associated with that kind of thing" (Fink and Cranor, Coils, 16). Throughout this story arc, it is clear that the inhabitants of Night Vale are not willing to condone racism, using this character as an example. But, by redeeming him through his sacrifice, they also acknowledge that racism is not the only defining characteristic of the tracker, or of any individual, just as happens with other themes running through the podcast. The tracker is shown to be a loyal inhabitant of the town, despite their rejection of his beliefs, and honored as a hero for his sacrifice. Even the worst people, the episode tells the reader, can have qualities that show them in a positive lightalthough, some things cannot be forgotten, even with the ultimate sacrifice.

In episode 18: “The Traveler" (Fink and Cranor, Mostly Void, 160-169), Cecil congratulates Tock Wallaby and his wife Hershel on the birth of their daughter Megan, who 
has been born as “an adult man's hand” (Fink and Cranor, Mostly Void, 167). Megan Wallaby is a character that reappears in episodes 34: "A Beautiful Dream" (Fink and Cranor, Coils, 8394), and 40: "The Deft Bowman" (Fink and Cranor, Coils, 146-156). These episodes reveal a complex, surreal story arc, which raises valid points about the treatment of disability in the real world. Everyone accepts Megan's gender identity without question; despite having the physical form of a male, adult hand, she is a female person. However, her disadvantaged position as a disabled person is highlighted in episode 34, when Cecil reports live from the Night Vale Elementary School, where the Parent-Teachers Association have been meeting with the School Board. Firstly, the broad implications of disability are foregrounded when it is reported that "the School Board was ... apathetic to petitions for a wheelchair ramp ... citing perilous struggles as one of the lessons children must absorb" (Fink and Cranor, Coils, 85), before Megan's parents request that a new computer be bought to assist their daughter, as "she is teased so much at school for not having a body" (Fink and Cranor, Coils, 86). While the disability Megan has been given in the podcast is absurd, the message behind it is not. The school installs an artificially intelligent computer to allow Megan to communicate with her peers, and to help her not feel so alone. As is usual in Night Vale, things go wrong, and the computer must be deactivated, leaving Megan once again alone, imitating the real life situation of children across the world that cannot join in with their peers due to a disability. Reflecting the levels of discrimination and isolation in the real world Cecil tells listeners, "There are children in wheelchairs who cannot get a simple ramp at a charter school...Likewise, there is a girl who is only a hand, and she needs a computer to help her be part of our community" (Fink and Cranor, Coils, 93-94). Juxtaposing the absurd with the real, Cecil reminds us (as the listeners in the real world) that discrimination is not confined to a character in a fictional podcast radio show, but rather is something that exists in the twenty- 
first Century, and in places that consider themselves advanced, such as the US and the UK, where these problems should not exist anymore.

Just as sexuality does not define Cecil and Carlos, disability does not define characters in Night Vale. While Megan is noteworthy for her physical differences, she is not the only character in Night Vale that has a disability: Cecil's niece Janice is a wheelchair user. This detail is introduced in episode 49: "Old Oak Doors" (Fink and Cranor, Coils, 243-273), a twopart episode, when Steve Carlsberg, (Cecil's brother-in-law and Janice's stepfather), is considering moving to nearby town Desert Bluffs. When he enquires about schools for Janice, he is told by Strexcorp employee Kevin that "Desert Bluffs schools are top-notch! Young Janice can take college prep courses as early as 12 . Our charter schools even have great medical programs, where they can heal her of all her problems" (Fink and Cranor, Coils 263). The "problems" Kevin is referring to is Janice's wheelchair use, stating that, "rather than build all those crazy ramps and elevators, we just fix people, so that they can become better, and more productive" (Fink and Cranor, Coils, 263). Again, this is reflective of real life: "nearly every culture" write David Mitchell and Sharon Snyder in their seminal text Narrative Prosthesis: Disability and the Dependencies of Discourse "views disability as a problem in need of a solution" (Mitchell and Snyder 48), a concept reflected in the words of Kevin, but which are refuted by Steve Carlsberg through his response: "Kevin of Desert Bluffs, you will not change, or fix, or do anything at all to my little girl" (Fink and Cranor, Coils, 264). Although Janice had appeared in several episodes of Welcome to Night Vale prior to this, her disability has been treated in the same way that the relationship between Carlos and Cecil iscompletely unremarked upon until it becomes relevant; Janice is defined by who she is, not by the wheelchair she sit in.

The refutation of disability being the defining aspect of a person is taken further in Episode 40: "The Deft Bowman", when the story arc surrounding Megan is completed, and 
she is given a body, in the form of an unidentified man, with a missing left hand, who offers to donate his own body, to allow Megan to live "in the body she was born without" (Fink and Cranor, Coils, 158). Once again, Cecil reminds the listener of the importance of compassion and understanding, saying that after successful surgery, "Megan has a long road of therapy ahead of her, learning how to ... everything ... but we believe in her, don't we Night Vale? That little girl is going to enjoy the childhood she feels she has missed out on ... If this is what she wants, we will support her, because she is beautiful" (Fink and Cranor, Coils, 155). Here, as elsewhere in Welcome to Night Vale, the listener is reminded that behind every disability, there is a person. Whether that person has the form of an adult hand, or is a wheelchair user, there is a human being with feelings, one who deserves compassion, understanding, and most of all support to become the person they want to be.

As well as highlighting the normativity of Carlos and Cecil's relationship, and identifying Megan as a girl (rather than having the gender of her body forced on her), Welcome to Night Vale seeks to show an equal level of understanding to other minority or discriminated people (a position elaborated in the novel as well). Just as the podcast allows characters to have disabilities, or be LGBT, and it is simply one of many things that make up each character, individuals in Night Vale are able to explore their own sense of identity, before deciding who they want to be, rather than being "forced to embody a fixed sexual identity" (Dhaenens 306) as happens in the real world. This is achieved in several ways, including having characters that are given a gender neutral pronoun, such as Sheriff Sam. Gender neutral pronouns are becoming increasingly common, as people are able to openly identify themselves in any way they want to. Sam is referred to as "them" and "they" throughout the podcast, and is voiced (and acted in the live shows) by trans actor Emma Frankland. Sheriff Sam has never been referred to by a gendered pronoun, and this gender neutrality allows the podcast to acknowledge the change in how personal pronouns are used. 
Linda D. Wayne sees gendered terminology as part of a problem that has "devoured our young not only through on-going violence, but though our failure to acknowledge that it consumes the spirit of those who do not fit within its confines" (Wayne 89). This is something that Welcome to Night Vale is not only aware of, but takes pains to refute. The presence of characters that are spoken of via a gender-neutral personal pronoun or by a gendered term that does not correspond to the physical make-up of a body shows this to good effect. While acknowledging that the concept of gender is a complicated and deeply personal thing, Welcome to Night Vale recognizes the difficulty in exploring identity, and this can be seen in the novel Welcome to Night Vale: A Novel through the introduction of a teenage character named Josh Crayton. Josh is a fifteen year old boy, who can take any shape he wants to, including "a curve-billed thrasher, or a kangaroo, or a Victorian-era wardrobe," and that "like most teenagers, he always was what he happens to be in that moment, until he never was that" (Fink and Cranor, Night Vale, 15). While the concept of a young person who can morph into any shape he desires is an exaggerated metaphor for being a teenager, the novel offers this as a way to understand the feelings of both being a teenager, and of being the parent of a teenager. Just as Night Vale enables difference in adults, children in Night Vale are able to explore their own sense of identity, and decide for themselves who they want to be. This includes not only representations of gender, but also of sexuality. Josh is not given a sexuality in the novel, be that gay, straight, trans, or bi. The novel states that "there was a girl Josh liked, who only liked Josh when he was bipedal" (Fink and Cranor, Night Vale, 15-16), and that "there was a boy Josh liked, who only liked Josh when he was a cute animal" (Fink and Cranor, Night Vale, 16). When he talks to his mother about dating, there is mention of both boys and girls that Josh has been (or is) interested in (Fink and Cranor, Night Vale, 143), but as with all other instances of sexuality, this is presented as being the norm-Josh is not pressured to fit into a pre-existing notion of gender and sexuality; unlike the real world as 
Dhaenens (306) explains, in Night Vale, there is no mould to fit into. Equally, in the same conversation, when Diane tells Josh she is dating Dawn, it is not a revelation of her sexuality, merely part of the discussion about dating. As Basimah Bishara says in episode 79, "Everyone's got their own thing, you know? ... So long as you are loved, it doesn't matter" (Vee).

While approximately half of the inhabitants of the world are (or identify as) female, there is "a pattern of gender hierarchy [that] has remained in which men continue to be advantaged not only in employment but also throughout much of society" (Ridgeway 1). Men occupy many of the most powerful positions in business and Government, across the world. The UN Women website states that, " 22.8 per cent of all national parliamentarians were women, as of June 2016" (UN Women). Even when woman are given positions of power, the media are sometimes more interested in how they appear than how they perform in their role. This is not the case in Night Vale, where female characters outnumber males in terms of their authority. The current Night Vale Mayor is Dana Cardinal, who succeeded Mayor Pamela Winchell—and one of the candidates in the election that elected Dana was the Faceless Old Woman Who Lives in your Home. Sixteen-year-old Tamika Flynn is considered by Cecil and Dana to be a hero, who led a guerrilla army against corporate giant Strexcorp when they attempted to take over Night Vale. She is also a member of the Night Vale City Council, having appointed herself on her sixteenth birthday. Dana Cardinal has faced opposition in her time as Mayor, such as an assassination attempt by Hiram McDaniels (a literal five-headed dragon), after her victory in the elections. What is important to note about these characters is that no one in Night Vale has any problems with there being several females in powerful positions, it is never mentioned, and unlike real world politics, there is no running commentary on the clothes the characters wear, whether they are suitable for the job they have, or whether personal circumstances will meant that they cannot perform their tasks, as 
has been the case in mainstream media news outlets regarding prominent female politicians across the world. As is the case with each of the concepts examined in this paper, the creators of Welcome to Night Vale are producing a fictional world that places the rights of the individual to be whomever they want to over those who want to enforce stereotypes, and who recognize that a person's worth does not depend on what they look like, who they love, or whether their inner identity matches that which the world sees.

The depiction of sexuality, gender, and identity in Welcome to Night Vale is an ideal, expressing the creators' vision of how media should be portraying characters. There are gay people, and as such there should be gay characters in fiction. But being gay should not be the defining characteristic of a person, just as being Muslim or Hispanic or even white should not be. Equally, a disability should not be the first thing that is associated with a person; there should be representations of people in wheelchairs, as this reflects reality. Equally, these depictions should not be plot points, or a way to include minorities, and this is what Night Vale excels at: representing people as equal, regardless of their individual characteristics. Most of the time, the listener is given information about a character through Cecil, and his descriptions do not usually include what the character looks like, until it becomes relevant; even Cecil himself is ambiguous. Other than his relationship with Carlos defining him as gay, there is very little description of him as a person; there are no clarifications of his ethnicity or race, for example. It is refreshing and heartening for a work of fiction to display a society where homophobia seemingly does not exist, and where cultural appropriation is treated with the contempt it deserves, and where each person is given the freedom to be who they want to be, and whilst this can be seen as simply another element of Night Vale's weird composition, it is also a critique of places where there is no freedom to live and to love as they want to. 


\section{Works Cited}

Adri, M. "Interview: Cecil Baldwin and Jeffrey Cranor of "Welcome to Night Vale"." 31 October 2013. newnownext.com. 04 January 2017. <http://www.newnownext.com/cecil-baldwin-jeffrey-cranorwelcome-to-night-vale/10/2013/>.

Butcher, Ryan. "Welcome to Night Vale's Cecil Baldwin: "Young people use Night Vale to begin the conversation about their own sexuality"." 25 September 2015. Gaytimes.co.uk. 28 December 2016. <http://www.gaytimes.co.uk/culture/9151/welcome-to-night-vales-cecil-baldwin-young-people-usenight-vale-to-begin-the-conversation-about-their-own-sexuality/>.

Dhaenens, Frederik. "Teenage Queerness: Negotiating Heteronormativity in the Representation of Gay Teenagers in Glee." Journal of Youth Studies (2013): 304-317. PDF.

Fink, Joseph and Jeffrey Cranor. Mostly Void, Partially Stars: Welcome to Night Vale Episodes, Volume 1. London: Harper Perennial, 2016.

-. The Great Glowing Coils of the Universe. New York: Harper Collins, 2016.

—. Welcome to Night Vale: A Novel. London: Orbit, 2015.

Goldman, Linda. Coming Out, Coming In: Nurturing the Well-being and Incluion of Gay Youth. Abingdon: Routledge, 2008. Print.

Mitchell, David T and Sharon L Snyder. Narrative Prosthesis: Disability and the Dependencies of Discourse. Ann Arbor MI: University of Michigan Press, 2001.

Moosavinia, S.R, N. Niazi Lorestan and Ghaforian Ahmad. "Edward Said's Orientalism and the Study of the Self and the Other in Orwell's Burmese Days." Studies in Literature and Language (2011): 102113. PDF.

Ridgeway, Cecilia L. Framed by Gender: How Gender Inequality Persists in the Modern World. Oxford: Oxford University Press, 2011. Print.

UN Women. "Facts and figures: Leadership and political participation." August 2016. UN Women. http://www.unwomen.org/en/what-we-do/leadership-and-political-participation/facts-and-figures. 05 January 2017.

Vee, Kenny. "Cecil Speaks: Episode 79 Lost in the Mail." 30 November 2015. Tumblr. 04 January 2017. <http://cecilspeaks.tumblr.com/post/134320284811/episode-79-lost-in-the-mail>.

Warner, Michael. The Trouble with Normal: Sex, Politics, and the Ethics of Queer Life. New York: The Free Press, 1999. Print.

Wayne, Linda D. "Neutral Pronouns: A Modest Proposal Whose Time Has Come." 2005. Canadian Woman Studies. PDF. 24 January 2017. 
$\mathrm{Wu}$, Connie. "Welcome to Night Vale: Where Queer is Normal and Normal is Bizarre." 29 September 2014. The Advocate. 02 Januarty 2017. <http://www.advocate.com/arts-

entertainment/2014/09/29/welcome-night-vale-where-queer-normal-and-normal-bizarre>. 